\title{
Review Paper on Genetic Variability and Divergence in Bread Wheat Triticum aestivum $\mathbf{L}$
}

\author{
Dereje
}

\begin{abstract}
Wheat (Triticum aestivum L.) is the second major food crop of the world in its importance next to rice. In Ethiopia the crop ranks third in terms of total production next to teff and maize. It is largely grown in the highlands of the country and constitutes roughly 20-30\% of the annual cereal production and plays an appreciable role of supplying the production with carbohydrates, proteins and minerals. Genetic diversity and variability are essential to meet the diversified goals of plant breeding such as breeding for increasing yield, wider adaptation, desirable quality, and pest and disease resistance. Genetic divergence analysis estimates the extent of diversity existed among selected genotypes. In common parlance, genetic variability and genetic diversity are considered synonym to each other which is erroneous. Genetic variability is the variation in alleles of genes or variation in DNA/RNA sequences in the gene pool of a species or population which expresses itself in terms of alternate forms in phenotype. Genetic diversity, on the other hand, is a broad term encompassing all the variability occurring among different genotypes with respect to total genetic make-up of genotypes related to single species or between species. Genetic similarity or dissimilarity can be compared by genetic distance between different individuals. Genetic distance can be used to measure the genetic divergence between different sub-species or different varieties of a species. Different characters of bread wheat show different contribution towards genetic variability and divergence. Estimate of heritability is very important to know the attribute to genetic variance not only in bread wheat but also in any crop plants.
\end{abstract}

Keywords: genetic variability, genetic divergence, wheat

\section{Introduction}

Wheat is an ancient food grain crop which belongs to the family Poaceae. It is a self-pollinated cereal crop with the 1$3 \%$ out crossing. After green revolution wheat occupied a prominent position among the world agricultural crops. Globally, bread wheat is most important species which covers 90 per cent of the cultivated area under wheat. It is largest cereal crop extensively grown as staple food sources in the world. It is one of the most important export and strategic cereal crop in the world and in Ethiopia in terms of production and utilization. It has been described as the 'King of cereals' because of the largest hectare it occupies, high productivity and the observable position it holds in the international food grain trade. It is a major source of energy, protein and dietary fibre in human nutrition ${ }^{[1]}$.

Cereals account for approximately two-thirds of all human energy intake and are grown on roughly half of the world's crop land ${ }^{[2]}$. It was reported that, eight cereal crops, wheat, rice, maize, barley, oat, rye sorghum and millets collectively account $99 \%$ of the world cereal production ${ }^{[3]}$. This also true for Ethiopia where the five major cereal crops; tef, maize, wheat, sorghum and barley have the largest share of cultivated land $(92.72 \%)$ and production $(95.8 \%)^{[4]}$. Wheat (Triticum aestivum L.) is the second major food crop of the world in its importance next to rice. In Ethiopia the crop ranks third in terms of total production next to teff and maize. It is largely grown in the highlands of the country and constitutes roughly $20-30 \%$ of the annual cereal production and plays an appreciable role of supplying the production with carbohydrates, proteins and minerals ${ }^{[5]}$. For a successful breeding program, the presence of genetic diversity and variability play a vital role.

Genetic diversity and variability are essential to meet the diversified goals of plant breeding such as breeding for increasing yield, wider adaptation, desirable quality, and pest and disease resistance. Genetic divergence analysis estimates the extent of diversity existed among selected genotypes ${ }^{[6]}$. Precise information on the nature and degree of genetic diversity helps the plant breeder in choosing the diverse parents for purposeful hybridization ${ }^{[7]}$. So the objective of this paper is to review the works done so far to know genetic variability and divergence and also its impact on different characters in Bread Wheat from different literatures

\section{Literature Review \\ 2.1 Concept of genetic diversity and variability}

Diversity is the essence of biological world. No two living things (even maternal twins) are exactly similar to each other. The difference in one or a few traits of the organism is referred

[Received 01 May 2020; Accepted 30 Aug 2020; Published (online) 30 Sep 2020] Publisher's Note: RCLSS stays neutral regard to jurisdictional claims published maps (c) (1) 
to as variability. In common parlance, genetic variability and genetic diversity are considered synonym to each other which is erroneous. Genetic variability is the variation in alleles of genes or variation in DNA/RNA sequences in the gene pool of a species or population ${ }^{[8]}$. This expresses itself in terms of alternate forms in phenotype. Genetic diversity, on the other hand, is a broad term encompassing all the variability occurring among different genotypes with respect to total genetic make-up of genotypes related to single species or between species. Genetic diversity can be measured by counting the number of different genes in a gene pool, but genetic variation can only be expected to occur and cannot be measured. Genetic variability thus, can be considered as the building blocks of genetic diversity ${ }^{[9]}$.

Genetic diversity is referred to the diversity present within different genotypes of same species. This is due to contrasting alleles of a gene in different individuals producing contrasting phenotypes. ${ }^{[10]}$ defined genetic diversity as the variation of heritable characteristics present in a population of the same species. The variation in heritable characters may express itself in the form of altered morphology, anatomy, physiological behavior or biochemical features. The genomic diversity can be defined as diversity at several gene-loci within an individual. Genetic diversity has received the greatest attention among agricultural workers.

Varieties developed with broader genetic base can sustain disease pressure better and are more adaptive to challenging agro-climatic conditions. The Food and Agriculture Organization of the United Nations (FAO) has estimated that as much as $75 \%$ of the genetic diversity in agricultural species has already been lost ${ }^{[11]}$. Therefore, there is a dire need to utilize the existing genetic variability in wheat for evolving high yielding varieties that have wide adoptability and are highly productive under varying climatic scenario/situation [12].

It was suggested that adequate scope is available for selection of superior and diverse genotypes for use in a programmed aimed at enhancing genetic yield potential of wheat. The higher the number of individuals in a cluster, the lesser is the diversity among them reported ${ }^{[13]}$. It has been wellestablished fact that more the genetically diverse parents used in hybridization program, greater will be the chances of obtaining high heterotic hybrids and broad spectrum variability in segregating generations ${ }^{[14]}$. Genetic diversity and relationship among genotypes is a prerequisite for any successful breeding program. Genetic diversity of plants determines their potential for improved efficiency and hence their use for breeding, which eventually may result in enhanced food production. Evaluation of genetic diversity levels among adapted, elite germplasm can provide predictive estimates of genetic variation among segregating progeny for pure-line cultivar development reported (Santosh et al., 2019). Genetic diversity facilitates breeders to develop varieties for specific traits like quality improvement and tolerance to biotic and abiotic stresses.

\subsection{Importance of genetic diversity}

Selection of elite genotypes with high per se performance for yield and yield contributing components with suitable genetic divergence among them is the most important and difficult job for starting any hybridization program. It would be possible to identify desirable genotypes from the genetic variability estimated, but it is difficult to expect any extra ordinary results from their progeny unless we have knowledge about divergence between them ${ }^{[15]}$.

Genetic diversity is the base for survival of plants in nature and for crop improvement. Diversity in plant genetic resources provides opportunity for plant breeders to develop new and improved cultivars with desirable characteristics, which include both farmer-preferred traits (high yield potential, large seed, etc.) and breeder-preferred traits (pest and disease resistance and photosensitivity, etc.). From the very beginning of agriculture, natural genetic variability has been exploited within crop species to meet subsistence food requirement. Later the focus shifted to grow surplus food for growing populations. Presently the focus is on both yield and quality aspects of major food crops to provide balanced diet to human beings. With changing climatic scenario, breeding of climate resilient varieties is becoming more important. The existence of genetic diversity represented in the form of wild species, related species, breeding stocks, mutant lines etc. may serve as the source of desirable alleles and may assist plant breeders in breeding climate resilient varieties ${ }^{[16]}$.

\subsection{Factors affecting genetic diversity}

Genetic diversity is primarily a function of sexual recombination. During meiosis, homologous chromosomes undergo crossing over which results in appearance of several new re combinations. Different factors affect the genetic diversity in plants. Evolutionary forces like selection, mutation, migration and genetic drift act continuously and results in continuous changes in allelic frequency in a population and affects the genetic diversity. Domestication or artificial selection favors few alleles at the cost of others resulting in increased frequency of selected alleles. Consequently, domestication reduces the genetic diversity when compared to the diversity in wild.

Natural selection also affects the genetic diversity considerably. Directional and stabilizing selection decreases while disruptive selection increases the genetic diversity. Mutation is also reported to increase genetic diversity [17]. Qualitative mutation expresses itself in the form of abrupt changes in morphological/anatomical/biochemical features. Quantitative or micro-mutations have smaller and gradual effects which accumulate over time and bring about changes. Mutation may also bring about several chromosomal aberrations. Smaller sub-lethal or non-lethal aberrations bring about genetic diversity in the form of altered phenotype. Mating system of crop plants also affect genetic diversity. Inbreeding reduces while out breeding increases genetic 
diversity. Genetic drift can lead to loss of rare alleles thereby reduces genetic diversity.

The physical distribution of individuals of a species also affects genetic diversity. Larger the physical distribution of individuals, lesser is the chances of having same genetic make-up. Some techniques like wide-hybridization, hybridization between incompatible types or introgression from previously isolated populations increase the genetic diversity as they result in generation of new phenotypes. In contrast, intra-specific hybridization reduces the genetic

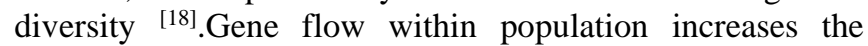
genetic diversity as new alleles are introduced.

\subsubsection{Intra and inter-cluster distances}

Inter-cluster distance is the main criterion for selection of genotypes using distance (D2) analysis ${ }^{[19]}$. The genotypes belonging to those clusters having maximum inter-cluster distance are genetically more divergent and hybridization between these genotypes of different clusters is likely to produce wide variability with desirable individuals ${ }^{[20]}$.

Cluster means were calculated for all the physiological and agronomic characters which exhibited considerable differences among the clusters. The mean performance of the clusters was used to select genetically diverse and agronomical superior genotypes reported [21]. The relative magnitude of intra cluster value indicates the variation among the genotypes present within a single cluster, the relative magnitude of inter cluster values indicates the level of genetic dissimilarity or divergence between the genotypes of paired combinations of the clusters ${ }^{[22]}$.

\subsubsection{Cluster analysis}

This analysis assumes discontinuities within the data. It describes the pattern of relatedness between genotypes based on evolutionary relationships or phenotypic performance. It is used to group similar lines/germplasm in one group and differentiate other groups. It is based on methods namely (i) Un weighted paired group method using arithmetic mean, (ii) Un weighted paired group method using centroid, (iii) Weighted paired group method using arithmetic mean, (iv) single linkages, (v) complete linkage) and (vi) Median linkage. Un weighted paired group method using arithmetic mean and Un weighted paired group method using centroid provide more accurate grouping information on breeding materials used in accordance with pedigrees and calculated results found most consistent with known heterotic groups than the other clusters ${ }^{[23]}$.

\subsubsection{Different characters towards genetic divergence}

On the basis of genetic diversity analysis, the maximum percent contribution towards genetic divergence was from grain yield per plot followed by biological yield per plant and minimum by harvest index and number of spikelet which confirms the findings of ${ }^{[24]}$ and of [25] The remaining characters did not show contribution towards genetic divergence reported by ${ }^{[26]}$. The other is reported by ${ }^{[20]}$ that the studded wheat character showed moderate to high variability and Considerable genetic divergence was also present among the in recombinant inbreed lines. This suggested that adequate scope is available for selection of superior and diverse genotypes for use in a programmed aimed at enhancing genetic yield potential of wheat.

\subsection{Genetic Variability}

Genetic improvement mainly depends upon the amount of genetic variability present in the population. The variability present in the genotypes was estimated by simple measure, namely range, mean, standard error, phenotypic and genotypic variance and coefficient of variation.

The phenotypic and genotypic variance and coefficient of variation were estimated according to the methods suggested by (Burton and Devane, 1953) ${ }^{[27]}$ as follows:

\section{$\sigma^{2} \mathrm{~g}=\underline{\mathrm{Mg}-\mathrm{Me}}$}

$\mathrm{r}$

Where; $\sigma^{2} \mathrm{p}=$ Phenotypic variance

$\sigma^{2} \mathrm{~g}=$ Genotypic variance

$\sigma^{2} \mathrm{e}=$ Environmental (error) variance (Error mean square)

$\mathrm{Mg}=$ mean square of genotypes

$\mathrm{Me}=$ mean square of error,

$r=$ Number of replication

Phenotypic coefficient of variation, $\mathrm{PCV}=\frac{\sqrt{\sigma 2 p}}{\mathrm{x}} \times 100$

Genotypic coefficient of variation, $G C V=\frac{\sqrt{\sigma 2 g}}{x} \times 100$

\subsubsection{Different character towards genetic variability}

The variation with respect to days to heading and days to maturity ranged from 69.33 days to 93 days, and 147.63 days to 172 days respectively, showing a wide range of variation among the genotypes for maturity reported by (Obsa Chimdesa et al., 2017) ${ }^{[28]}$ which is contrast to the findings of (Ullah et al., 2011) and (Degewione et al., 2013) who reported the range of 16.40 to 71 days and 59 to 177 days for days to heading and days to maturity, respectively. The variation with respect to days to heading and days to maturity was also contradicting with the findings of ${ }^{[18]}$ which days to 50 percent heading ranged from 101 to 112 and days to maturity ranged from 141 to 148.33 days. So that regarding with respect to days to heading and days to maturity the findings of three authors was opposing with each other.

\subsubsection{Estimate of heritability in genetic variability}

Heritability is the percentage of phenotypic variance that is attributed to genetic variance. It was reported (Ishan Ahmed et al., 2018) that heritability was high for all studied traits, high heritability indicates that the environmental influence is minimal on traits and it may be useful for wheat breeding programs, especially targeted for improvement of nutrition traits.

High broad sense heritability was found for the grains per spike $(71.01 \%)$, plant height $(93.58 \%)$, panicle length (78.48\%) and yield (66.71\%). Quantitative traits with high 
genetic gain and high heritability are important for the selection of genotype at early stages in breeding program ${ }^{[28]}$. The low broad sense heritability estimate indicated low genetic potentials for the traits under investigation, effect of environment in determining measured traits and absence of predominant role of additive gene action [33, 34]. ${ }^{[33]}$ also reported high heritability estimates for grain yield, number of spikelets per spike, number of seeds per spike, plant height, 100 -seed weight and number of tillers per plant. The number of grains per spike and yield has good genetic gain and they may control through additive gene effects therefore selection may be effective in early generations for these traits. The combination of high heritability and genetic gains are important indicators of the predominant role of additive gene action in characters (Mondal, 1997). High heritability for spike length and plant height coupled with low genetic gain indicates non-additive gene effects for these traits. Therefore, there seems to be a limited scope of improvement while using these traits.

Heritability estimate for characters reported by (Obsa Chimdesa et al., 2017) was highly heritable in peduncle length $(84.67 \%)$ followed by days to maturity $(83.41 \%)$, days to heading $(82.48 \%)$, grain filling period (81.23), spike length $(71.1 \%)$, plant height $(69.95 \%)$ and kernels/spike $(62.29 \%)$. These results clearly demonstrate that environment had low influence on the expression of the characters suggesting direct selection using these characters as major contributors of yield components. Spikelet per spike (58.69\%), 1000 seed weight $(49.52 \%)$, grain yield per hectare $(43.57 \%)$, number of productive tillers/meter $(35.63 \%)$, harvest index $(35.33 \%)$, biological yield/plot (34.65\%) and number of tillers/plant $(33.33 \%)$ shows moderate level of heritability which may be due to influence of the environment on the polygenic nature of these trait. Low heritability was not found among the studied characters this indicates the possibility of including all the characters in order to select desirable genotypes

Heritability estimates which was reported by ${ }^{[29]}$ was low for number of tillers per plant (20\%), grains per spike $(26.81 \%)$, days to maturity $(30.13 \%)$, spike length $(36.66 \%)$ and 1000 grain weight $(38.68 \%)$ which is contradicting with the findings of (Obsa Chimdesa et al., 2017) and moderately high for plant height (45.79\%) and very high for days to 50 percent heading (84.73\%) and grain yield (99.83\%). (Aafia, et al., 2000) and (Ajmal, S et al., 2009) have also noted low to high estimates of heritability and genetic advance for all these traits except plant height.

Quantitative traits with high genetic gain and high heritability are important for the selection of genotype at early stages in breeding program ${ }^{[30]}$. The low broad sense heritability estimate indicated low genetic potentials for the traits under investigation, effect of environment in determining measured traits and absence of predominant role of additive gene action [31,32] also reported high heritability estimates for grain yield, number of spikelet's per spike, number of seeds per spike, plant height, 100-seed weight and number of tillers per plant.

\section{Summery and conclusion}

Genetic diversity and variability is essential to meet the diversified goals of plant breeding such as breeding for increasing yield, wider adaptation, desirable quality, and pest and disease resistance. Genetic improvement mainly depends upon the amount of genetic variability present in the population. To initiate any crop improvement program, identification of desirable and genetically divergent parents is a pre-requisite. So that Precise information on nature and degree of genetic divergence helps the plant breeder in selecting the genetically diverse parents for the purposeful hybridization. Information on the genetic parameters, heritability and genetic advance can help the breeder to evolve suitable cultivars within a short time. The knowledge on heritability of traits is helpful to decide the selection procedure to be followed to improve the trait in a situation. Traits like plant height, thousand kernel weight, number of productive tillers/meter, number of tillers/plant and grain yield per plot can be considered as suitable selection criteria for the development of high yielding bread wheat varieties with better quality

The other one is genetic similarity or dissimilarity which can be compared by genetic distance between different individuals. Genetic distance can be used to measure the genetic divergence between different sub-species or different varieties of a species. Different characters of bread wheat show different contribution towards genetic variability and divergence. Estimate of heritability is very important to know the attribute to genetic variance not only in bread wheat but also in any crop plants

\section{References}

[1]. Aafia, S., N. A. Muhammad and M. M. Saleem. 2000. Statistical genetic parameters, heritability and graphical analysis in $8 \mathrm{x}$ wheat diallel cross under saline conditions. Annals. Agric. Sci. 45:257-280.

[2]. Ajmal, S. U., N. Zakir and M. Y. Mujahid. 2009. Estimation of genetic parameters and character association in wheat. J. Agric. Boil. Sci.1 (1):15-18.

[3]. Aremu CO, Adebayo MA, Ariyo OJ, et al. Classification of genetic diversity and choice of parents for hydridization in cowpea vigna unguiculata (L) walip for humid savanna ecology. African J of Biotech. 2007;6(20):2333-2339.

[4]. Arunachalam, V. 1981. Genetic distance in plant breeding. Indian J. Genet. 41: 226-236.

[5]. Arya, V.K., Singh J., Kumar L., Kumar R., Kumar P., Chand, P. (2017) Genetic variability and diversity analysis for yield and its components in wheat (Triticum aestivum L.). Indian J. Agric. Res.; 51(2):128-134.

[6]. Baranwal DK, Mishra VK, Vishwakarma MK, Yadav PS, Arun B (2012). Studies on genetic variability, correlation and path analysis for yield and yield contributing traits in wheat (T. aestivum L. emThell.). Plant Arch., 12: 99-104. 
[7]. Bhandari HR, Bhanu AN, Srivastava K, et al. Assessment of genetic diversity in crop plants - an overview. Adv Plants Agric Res. 2017; 7(3):279286.

[8]. Burton, G. W. and E. H. Devane, 1953. Estimating heritability in Tall Fescue (Festuca arundinacea) from replicated clonal material. Agronomy Journal 45: 487-488.

[9]. CSA (Central Statistical Agency), 2012. Crop production forecast sample survey, 2012/13. Report on Area and Crop Production forecast for Major Crops (for private Peasant Holdings 'Meher' season). Addis Ababa, Ethiopia.

[10]. Degewione A., Dejene T., and Sharif M., 2013. Genetic variability and traits association in bread wheat (Triticum aestivum L.) genotypes. International Research Journal of

a. Agricultural Sciences Vol. 1(2): 19-29.

[11]. Dobariya, K.L., Ribadia, K.H., Padhar, P.R., Ponkia, H.P. (2006). Analysis of genetic divergence in some synthetic lines of bread wheat (Triticum aestivum L.). Advances in Plant Sciences. 19(1): 221-225.

[12]. Dwivedi AN, Pawar IS, Shashi M and Madan V (2002) Studies on variability parameters and character association among yield and quality attributing traits in wheat. Haryana

[13]. Agric. Univ. J. Res. 32: 77-80.Fakhar Uddin, Fida Mohammad and Sheraz Ahmed Genetic divergence in wheat recombinant inbred lines for yield and yield components Academia Journal of Agricultural Research 3(10): 303-307, October 2015 DOI: 10.15413/ajar.2015.0139

[14]. FAO (Food and Agriculture Organization of the United Nations), 2011. FAOSTAT: World Crop production data. Accessed on 16 December, 2014. Available at: (http://www.faostat.fao.org/site

[15]. Hawkes JG, Maxted N, Ford-Lloyd BV (2000). The exsitu conservation of plant genetic resources. Kluwer Academic, Dordrecht, the Netherlands

[16]. Ishan Ahmed, Jitendra Kumar, Neha Goel, Vinod Kumar Mishra and Pradeep Kumar Sharma. 2018. Characterization of Variability, Genetic Divergence and Character Association in Wheat Germplasm of SWRS in Respect of Nutrition and Yield Traits. Int.J.Curr.Microbiol.App.Sci. 7(05): 303-314. doi: https://doi.org/10.20546/ijcmas.2018.705.039

[17]. Johnson HW, Robinson $\mathrm{HE}$ and Comstock RE (1955) Estimates of genetic and environmental variability in soybean. Agron. J. 47: 314-318. DOI:

a. 10.2134/agronj1955.00021962004700070 009x

[18]. Khare M.Rangare N.R.and Singh,R.P,(2015). Evaluation of genetic diversity in Mexican wheat (TriticumaestivumL.)genotypesforquantitativeandq
ualitativetraits.InternationalJournalofPlantProtectio n, 8(1):77-80

[19]. M. Yaqoob. Estimation of genetic variability, heritability and genetic advance in wheat. J. Agric. Res., 2016, Vol. 54(1):1-14

[20]. Mecha B, Alamerew S, Assefa A, Assefa E, Dutamo D. Genetic variability, heritability and genetic advance for yield and yield related traits in bread wheat (Triticum aestivum L.) genotypes. Global Journal of Science Frontier Research: D Agriculture and Veterinary. 2016; 16:2249-4626.

[21]. Mondal AB, Sadhu DP and Sarkar KK (1997) Correlation and path analysis in bread wheat. Environ. Ecol. 15: 537-539.

[22]. Mondal, M.A.A., Improvement of potato (Solanum tuberosum L.) through hybridization and in vitro culture technique. PhD Thesis. Rajshahi University, Rajshahi, Bangladesh, 2003.

[23]. Obsa Chimdesa, Wassu Mohammed, Firdissa Eticha. Analysis of Genetic Variability Among Bread Wheat (Triticum aestivum L.) Genotypes for Growth, Yield and Yield Components in Bore District, Oromia Regional State. Agriculture, Forestry and Fisheries. Vol. 6, No. 6, 2017, pp. 188199. doi: 10.11648/j.aff.20170606.12

[24]. Osawaru ME, Ogwu MC, Aiwansoba RO. Hierarchical approaches to the analysis of genetic diversity in plants: a systematic overview. University of Mauritius Res J. 2015;21:1-33.

[25]. Sachan and Singh (2003) Genetic variability in some metric traits and its contribution to yield in wheat (Triticum aestivum L.). Progressive Agric. 3: 152153

[26]. Santosh, J.P. Jaiswal, Anupama Singh and Naveen Chandra Gahatyari. 2019. Genetic Diversity Analysis in Bread Wheat (Triticum aestivum L.em.Thell.) for Yield and Physiological Traits. Int.J.Curr.Microbiol.App.Sci. 8(02): 3059-3068. doi: https://doi.org/10.20546/ijcmas.2019.802.358

[27]. Schulthess, U.B., Feil, J., Jutzi, S.C. Yield independent variation in grain nitrogen and phosphorus concentration among Ethiopian wheat. Agron. J. (2000)89(3): 497-506

[28]. Singh, S.K., Singh B.N., Singh, P.K. and Sharma, C.L. (2006). Genetic divergence of exotic germplasm lines in wheat (T. aestivum L.). Indian J. Plant Genet.Resources. 19 (2):218-220.

[29]. Swingland IR. Biodiversity. Definition of Encyclopedia of Biodiversity. 2001;1:377-390

[30]. Shivendra Pratap Singh, Pooran Chand, Vipin Kumar Singh and Prakriti Tomar. Characterization and assessment of genetic divergence in bread wheat (Triticum aestivum L.) International Journal of Chemical Studies 2018; 6(6): 2790-2792

[31]. Ullah K., Khan S. J., Irfaq M., Muhammad T., and Muhammad S., 2011. Genotypic and phenotypic 
variability, heritability and genetic diversity for yield components in bread wheat (Triticum aestivum L.) germplasm. African

[32]. Journal of Agricultural Research Vol. 6(23): 52045207.

[33]. USAID (United States Agency for International Development), 2013. Feed the future food security innovation center. Accessed on March, 2014. Web site: http://www.feedthefuture.gov/research.

[34]. Yilmaz A, Boydak E. The effects of cobalt-60 applications on yield components of cotton (Gossypium barbadense L.). Pak J Bio Sci. 2006;9(15):2761-2769. 